\title{
Selective zeolite catalyst for alkylation of benzene with ethylene to produce ethylbenzene
}

\author{
Mohammed C. Al-Kinany • Hamid A. Al-Megren • \\ Eyad A. Al-Ghilan • Peter P. Edwards • Tiancun Xiao • \\ Ahmad. S. Al-Shammari • Saud A. Al-Drees
}

Received: 4 July 2012/ Accepted: 27 October 2012

(c) The Author(s) 2012. This article is published with open access at Springerlink.com

\begin{abstract}
In this work, a selective catalyst of BXE ALKCAT zeolite has been developed with about $30 \%$ of ZSM-5 balanced with kaolinite, and applied for gas-phase alkylation of benzene (BZ) with ethylene (E). The catalyst has been tested in a fixed-bed down-pass flow reactor under different conditions of temperatures ranging between 300 and $450{ }^{\circ} \mathrm{C}$ with $\mathrm{BZ}$ to $\mathrm{E}$ mole ratios ranging between $1: 1$, 3:1 and 6:1 under atmospheric pressure and space velocity ranges between 0.1 and $150 \mathrm{~h}^{-1}$. The BXE ALKCAT zeolite catalyst has been characterized using: scanning electron microscope, X-ray diffraction, specific surface area, pore volumes, pore size distributions, X-ray photoelectron spectroscopy, and differential thermal analysis, and thermo-gravimetric analyses. Ethylbenzene was the main product of alkylation, and diethylbenzene isomers (ortho-, meta-, and para-) were the minor products. In the case of 1:1 mol ratio of BZ to E, the selectivity of EB about $85.5 \%$ at highest conversion of BZ was obtained after $1 \mathrm{~h}$ of reaction on stream at $450{ }^{\circ} \mathrm{C}$. A decrease in the temperature to $300{ }^{\circ} \mathrm{C}$ (with $1: 1 \mathrm{~mol}$ ratio) caused the selectivity of EB to decrease to $73.0 \%$. EB and DEBs yields were found to increase with increasing the reaction temperature and decreasing the mole ratio of $\mathrm{BZ}$ to $\mathrm{E}$. The
\end{abstract}

M. C. Al-Kinany · H. A. Al-Megren (凹) .

E. A. Al-Ghilan · S. A. Al-Drees

Petrochemicals Research Institute, King Abdulaziz City for Science and Technology, P.O.Box 6086, Riyadh 11442, Saudi Arabia

e-mail: almegren@kacst.edu.sa

P. P. Edwards · T. Xiao · Ahmad. S. Al-Shammari .

S. A. Al-Drees

Inorganic Chemistry Laboratory, Wolfson Catalysis Centre, KACST-Oxford Petrochemicals Research Centre (KOPRC), University of Oxford, South Parks Road, Oxford OX1 3QR, UK conversion of BZ appeared to be depending strongly on mole ratio of $\mathrm{BZ}$ to $\mathrm{E}$ at a given temperature. The study has shown that the BXE ALKCAT zeolite is active as a catalyst for the alkylation reaction and selective to EB compared with other zeolite catalysts.

Keywords Alkylation - Ethylation · Ethylbenzene · Zeolite

\section{Introduction}

Ethylbenzene is important in the petrochemical industry as an intermediate in the production of styrene, which in turn is used for making polystyrene, a common plastic material. In industry, EB is mainly manufactured by the alkylation of benzene with ethylene via two methods, i.e., the gas-phase method [1-5] and the liquid-phase method. The gas-phase method is the Mobil-Badger technology, which used mostly molecular sieve catalyst, e.g. ZSM families like ZSM-5 and ZSM-22, because of their unique advantages of highly selective, less toxic, environmentally friendly and readily reproducible in catalytic reactions $[6,7]$. Another reason for ZSM-5 zeolite catalyst being used in alkylation of benzene with ethylene is that its proper pore size can increase the EB diffusion, while it prevents the polyethylbenzene (PEB) to diffuse through the catalyst $[3,4,8,9]$. However, ZSM-5 zeolite has high acid strength and acid amount, which easily catalyses the carbon formation from ethylene $[10,11]$. Therefore, in this process, the benzene to ethylene molar ratio is about 8-16 which increases the needed energy in the fraction unit for the separation of EB from benzene and transethylbenzene.

In addition, the gas-phase method normally is carried out under moderate pressure (1.0-20.8 MPa) and high 
temperature (573-773 K), which leads to higher energy consumption, more cooling systems and strict requirements for the apparatus. Many years' industrial operation results showed that the pure ZSM-5 based catalyst suffers from several disadvantages. For example, more byproducts are produced, especially toluene at about 1,000-2,000 ppm, which is much higher than the levels required by the downstream processes; the selectivity toward ethyl benzene is low, and the deactivation of the catalyst is so serious that it requires periodic regeneration. The byproducts and the rapid deactivation of the ZSM-5 catalyst for the alkylation are believed to be due to its strong acidity.

Kaolinite has been widely used as binder and balanced material for zeolite catalyst, because it has global pore with 105 A mean pore size, which has little effect on the diffusion of the reactants products [12-14]. It also allows the easy process and extrudation of the acid catalyst. In this work, $30 \mathrm{wt} \%$ of ZSM-5 catalyst has been mixed with kaolinite and tested for benzene alkylation with ethylene at low benzene to ethylene ratio; the results show that the low content of ZSM-5 zeolite catalyst is suitable for low benzene to ethylene ratio and high stability. This may be promising to reduce the cycle and save energy.

\section{Experimental}

\section{Catalyst preparation}

The catalyst, BOX ALKCAT has been prepared using prilling process The main active component, e.g., ZSM-5 $(\mathrm{Si} / \mathrm{Al}=25)$ is mixed with kaolinite at 30:60 and $10 \%$ of alumina as the binder. These are mixed with a small amount of water to form a slurry. The slurry is shaped into particles using a prilling machine (36MM, SZCX 160/45, made in China). The resultant catalyst particles contain $30 \mathrm{wt} \%$ of ZSM-5, which is then dried in static air at $450{ }^{\circ} \mathrm{C}$ for $5 \mathrm{~h}$ to remove the moisture and volatile impurities.

\section{Chemicals and catalysts}

All chemicals were analytical grade; benzene, ethylbenzene (Fluka Chemie 99.5\%), o-diethylbenzenes (Fluka Chemie $98.9 \%$ ), $m$-diethylbenzenes (Fluka Chemie $98.9 \%$ ), p-diethylbenzenes (Fluka Chemie $98.9 \%$ ), 1,3,5triethylbenzene (Fluka Chemie $98 \%$ ) and 1,2,4,5-tetraethylbenzene (Fluka Chemie $98 \%$ ) were used directly without further purification. Ethylene gas (purity $>99.95 \%$ ) was obtained from M/s. Abdullah Hashim for industrial gases. Hexane (Fluka Chemie) was of high grade and spectroscopically highly pure (purity $>99.98 \%$ ).
Catalyst characterization

$X$-ray diffraction $(X R D)$

Measurements were conducted using Brucker diffractometer D8 which utilizes Ni-filtered $\mathrm{CuK} \alpha$ radiation $(\lambda=1.54 \AA)$. Diffraction patterns were obtained with $\mathrm{X}$-Ray gun operated at $40 \mathrm{kV}$ and $30 \mathrm{~mA}$ with a scan rate of $4 \%$ min $(2 \theta)$.

\section{Scanning electron microscope (SEM)}

The crystal size and morphology of BXE ALKCAT catalyst were determined with a FEI-NNL200, $5 \mathrm{kV}$ and work distance $5.0 \mathrm{~mm}$. The silicon and aluminum contents of the BXE ALKCAT zeolites were obtained using EDAX Ametek-Model 60040, 10 kV.

\section{X-ray photoelectron spectroscopy (XPS)}

XPS studies were recorded using JEOL JPS 9010MC photoelectron spectrometer, using $\mathrm{MgK} \alpha(1,253.6 \mathrm{eV})$ radiation from an $\mathrm{X}$-ray source operating at $10 \mathrm{kV}$ and $20 \mathrm{~mA}$, and the base pressure in the analysis was kept in the range from $5 \times 10^{-10}$ to $1 \times 10^{-9}$ mbar. The binding energies (BE) were referenced to the $\mathrm{C} 1 \mathrm{~s}$ level at $284.9 \mathrm{eV}$. A estimated error of $\pm 0.1 \mathrm{eV}$ can be assumed for all measurements.

\section{Physisorption analysis}

Textural properties were determined by nitrogen adsorption-desorption experiments. The isotherm was measured using a Micrometrics ASAP 2010 system. BET surface area, pore volume and pore size measurements studies were carried out using physisorption technique. The adsorption for nitrogen was measured at $77 \mathrm{~K}$. Prior to the experiments, the samples were degassed under vacuum at $250{ }^{\circ} \mathrm{C}$ for $6 \mathrm{~h}$. The surface area was calculated using the BET method based on adsorption data. The pore size distribution for mesopore was analyzed from desorption branch of the isotherm by the Parrett-Joyner-Halenda method and the pore size distribution for micropore was analyzed by HK method.

Differential thermal analysis (DTA) and thermo-gravimetric analyses (TGA)

DTA and TGA were recorded on Perkin Elmer (DTA-7) with thermal analysis controller TAC-7/DX. The catalyst samples were recovered after reaction and dried under vacuum before being analyzed by TGA. 


\section{Catalyst evaluation}

The catalytic behavior of BXE ALKCAT zeolite catalyst for the alkylation of benzene with ethylene was studied in a conventional bench-top pilot plant, as shown in Fig. 1, fitted with a fixed-bed down-flow stainless steel reactor with an internal diameter of $5 \mathrm{~mm}$ and $35 \mathrm{~cm}$ long at atmospheric pressure and temperature ranging between 300 and $450{ }^{\circ} \mathrm{C}$. The reactor was coupled to a mass flow meter to measure un-reacted ethylene. The reactor was heated in an electrical furnace, and the reactor's temperature was measured by a thermocouple located inside the furnace and was controlled by a temperature controller (Cole-Parmer Digi-sense).

Each time, $1.0 \mathrm{~g}$ of catalyst was loaded in the middle of the reactor. The feed stock of the alkylation reaction consisting of benzene and ethylene was introduced at the top of the reactor. Normally, the flow rate of ethylene was 2-22 $\mathrm{ml} / \mathrm{min}$ with benzene to ethylene mole ratios ranging from 1:1 to 6:1, respectively, under atmospheric pressure. The flow rate of ethylene was adjusted through a separate thermal mass flow controller (Bronkhorst). The flow rate of benzene was controlled through a one channel syringe pump (Cole-Parmer). The alkylation reaction products were collected in a cooled condenser attached to the end of the reactor and was analyzed using a gas chromatograph.

The activity of the catalysts, yield and selectivity of alkylbenzenes (ethylbenzene, and $o-, p$ - and $m$-diethylbenzene) and benzene conversion were studied at 300 , 350,400 and $450{ }^{\circ} \mathrm{C}$ by changing the benzene to ethylene mole ratios from 1:1 to $6: 1$ at each temperature. Blank reactor runs were conducted and no significant conversions were observed under the conditions of alkylation reaction.

Gas chromatographic analysis

Gas chromatographic analysis of the alkylation products was performed on Varian 3800 series instrument fitted with a flame ionization detector and a $50 \mathrm{~m} \times 0.25 \mathrm{~mm}$ glass open tubular capillary PONA column. The column temperature was programmed as an initial temperature of $30{ }^{\circ} \mathrm{C}$ for $15 \mathrm{~min}$, then $60{ }^{\circ} \mathrm{C}$ for $20 \mathrm{~min}$ (heating rate $1{ }^{\circ} \mathrm{C} / \mathrm{min}$ ) and finally $200{ }^{\circ} \mathrm{C}$ for $20 \mathrm{~min}$ (heating rate $2{ }^{\circ} \mathrm{C} / \mathrm{min}$ ).

The FID detector temperature was $250{ }^{\circ} \mathrm{C}$ and that of injector $250{ }^{\circ} \mathrm{C}$ (for manual injection). The maximum column temperature at which the stationary phase is stable is $200{ }^{\circ} \mathrm{C}$. Flow rates of zero air $\left(80 \mathrm{lb} / \mathrm{in}^{2}, 300 \mathrm{~cm}^{3} / \mathrm{min}\right)$, hydrogen $\left(40 \mathrm{lb} / \mathrm{in}^{2}, 30 \mathrm{~cm}^{3} / \mathrm{min}\right)$ and $\mathrm{He}$ carrier gas $\left(80 \mathrm{lb} / \mathrm{in}^{2}, 25 \mathrm{~cm}^{3} / \mathrm{min}\right)$ were applied. Occasional checking showed that the flow rate was almost constant.

External standardization method is the analytical method which has been employed for the quantitative analysis of the alkylation products. The GC instrument was calibrated by analyzing the known composition of a prepared calibration mixture (standard mixture) of pure components of benzene, ethylbenzene, diethylbenzenes $(o-, p-$, and $m$-), triethylbenzene and tetraethylbenzene. GC chromatogram of standard mixture is shown in Fig. 2.
Fig. 1 Bench-top pilot plant fitted with fixed bed reactor. 1 two-way valve, 2 flow meter, 3 check valve, 4 pump, 5 threeway valve, 6 reactor 7 gas chromatography, 8 recorder

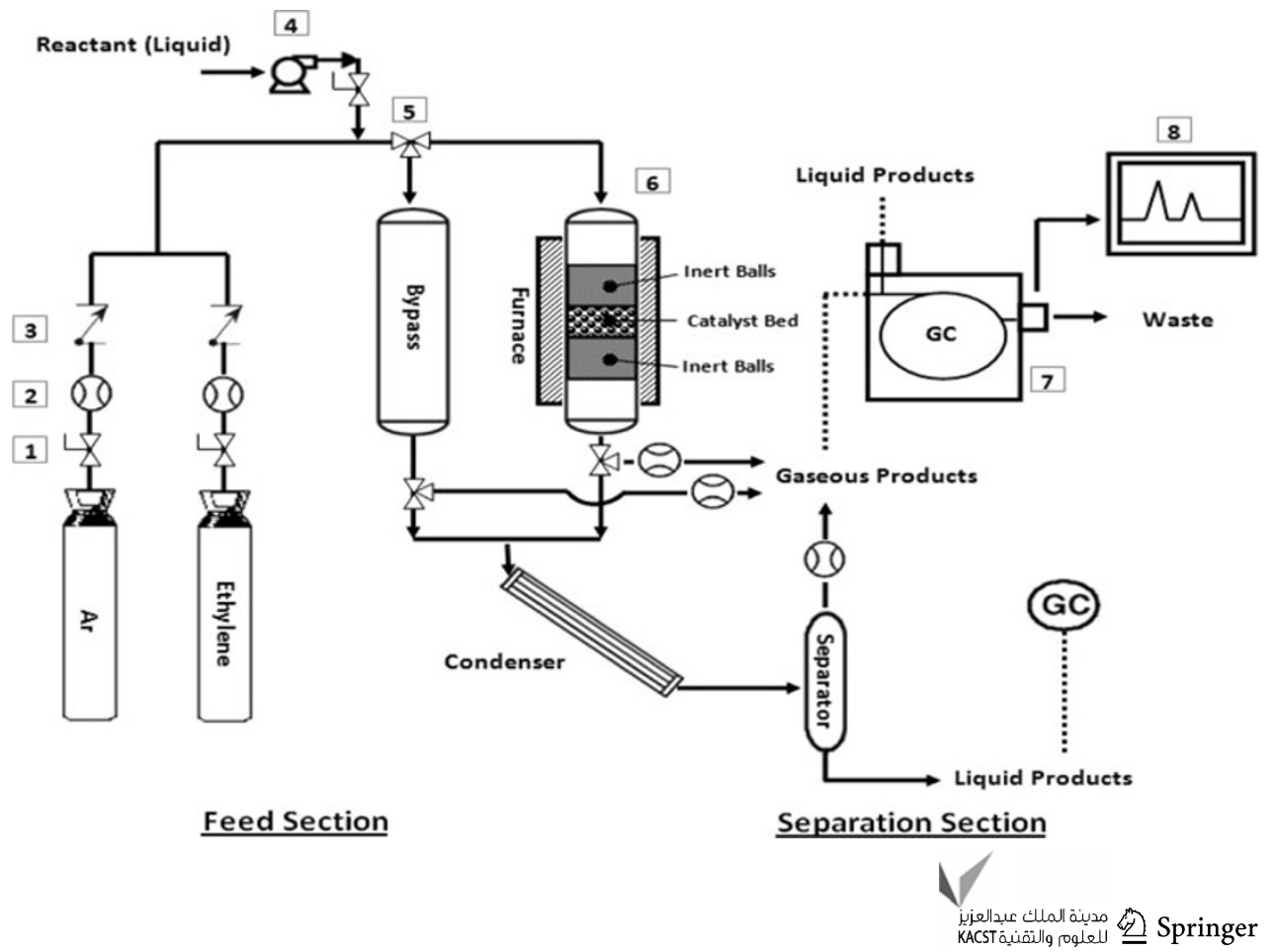


Fig. 2 Typical separation of the standard mixture of: solvent, benzene, ethylbenzene, diethylbenzenes $(o-, m-$, and $p$-), and triethylbenzene

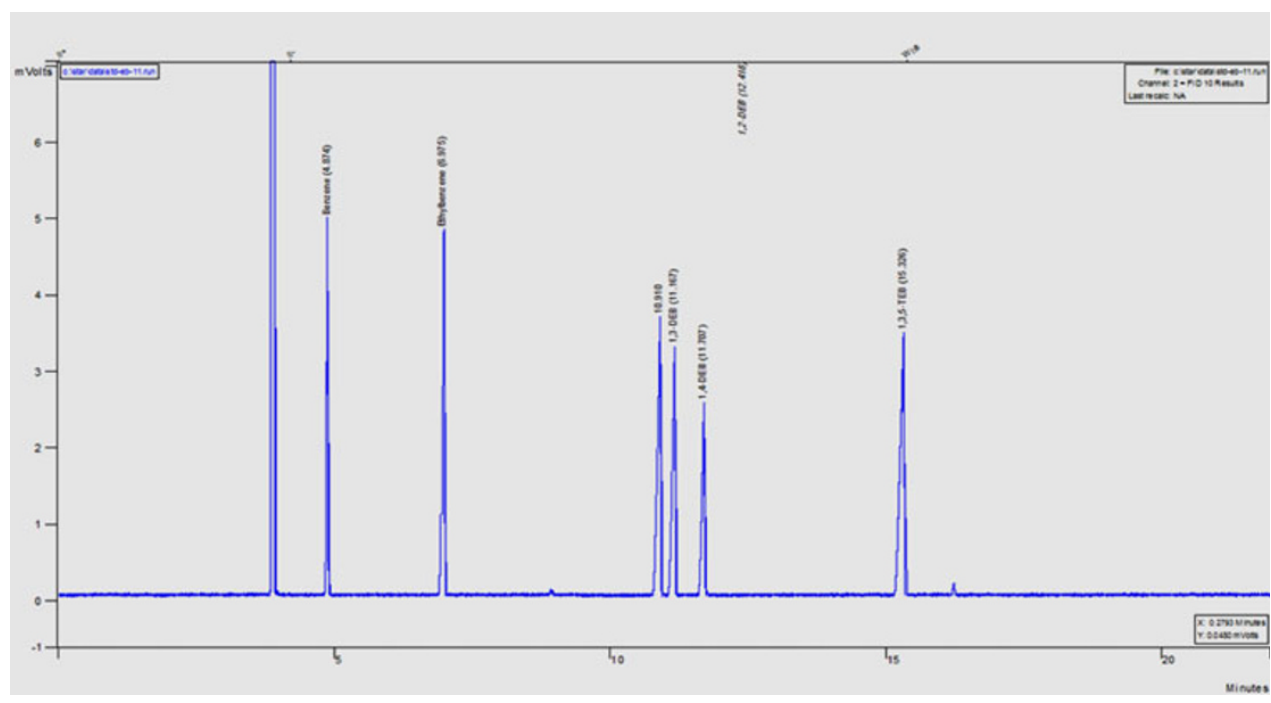

Gas chromatography/mass spectroscopy analysis

Identification of the alkylation products was performed on Shimadzu GC/MS-QP2010. The GC fitted with PONA $50 \mathrm{~m}$ glass open tabular capillary column. The column temperature was programmed as an initial temperature of $30{ }^{\circ} \mathrm{C}$ for $15 \mathrm{~min}$, then $60^{\circ} \mathrm{C}$ for $20 \mathrm{~min}$ (heating rate $1{ }^{\circ} \mathrm{C} / \mathrm{min}$ ) and finally $200{ }^{\circ} \mathrm{C}$ for $20 \mathrm{~min}$ (heating rate $2{ }^{\circ} \mathrm{C} / \mathrm{min}$ ). The injector temperature was $250{ }^{\circ} \mathrm{C}$. Flow rate of $\mathrm{He}(13 \mathrm{kPa}, 155 \mathrm{ml} / \mathrm{min})$ was applied: Ion source temperature $200{ }^{\circ} \mathrm{C}$, interface temperature $250{ }^{\circ} \mathrm{C}$ and detector voltage $0.7 \mathrm{kV}$.

\section{Results and discussion}

\section{Catalyst characterization}

\section{Physicochemical properties of BXE ALKCAT zeolite}

Figure 3 shows SEM images of BXE ALKCAT zeolite. It can be seen from the figure that aggregates of spherical beads with irregular shape are prominent. The spherical do not have well-defined morphologies and most of the deformed spherical beads appear to be more than $1 \mu \mathrm{m}$ in size.

\section{BET surface area, pore volume and size of zeolite}

$\mathrm{N}_{2}$ adsorption/desorption analysis is a useful tool for examining textural characteristics of porous materials. The isotherms for BXE ALKCAT zeolite are displayed in Fig. 4.

The isotherm of the sample is a hysteresis loop at relatively high pressure $\left(p / p_{0}\right)$, indicating that the crystal sizes are small and present a relatively high external surface area with little mesoporosity. The textural parameters of the corresponding sample have high BET surface area $\left(228.5 \mathrm{~m}^{2} / \mathrm{g}\right)$, pore volume $\left(0.174 \mathrm{~cm}^{3} / \mathrm{g}\right)$ and pore size (30.4 $\AA$ ) which is attributed to porous kaolinite, where the pore of kaolinite can range very wide. The use of large pore kaolinite also helps the diffusion of the reactants, and dilutes the acidic sites, which is the goal to design the catalysts.

\section{$X$-ray diffraction analysis}

Figure 5 shows XRD pattern(s) of BXE ALKCAT zeolite. The high intensity of peaks in the XRD patterns indicated that the BXE ALKCAT zeolite samples are highly crystalline materials, in which the main phase is kaolinite and whose main diffraction peaks are seen at $2 \theta$ of $11^{\circ}$ and $25^{\circ}$, which is in agreement with the catalyst composition. The rest main diffraction peaks all come from the calcined ZSM-5 sample. As the ZSM-5 only accounts for $30 \mathrm{wt} \%$ of the catalyst, its diffraction peaks are relatively weak.

\section{$X$-ray photoelectron spectroscopy data of BXE ALKCAT zeolite}

The XPS technique was applied to investigate the binding energies of the states of element between $\mathrm{Si}$ and $\mathrm{O}$. The XPS data of curve fitting for the zeolite sample were recorded as shown in Figs. 6 and 7. All binding energy referred to $\mathrm{C} 1 \mathrm{~s}=285.0 \mathrm{eV}$. Data for the elements detected were $\mathrm{Si} 2 \mathrm{P}_{1 / 2}$, and $\mathrm{O} 1 \mathrm{~s}$ at binding energies of 102.1 and $532.1 \mathrm{eV}$.

It is shown that the surface compositions of the catalyst are mainly $\mathrm{O}, \mathrm{Si}$ and $\mathrm{Al}$, with $\mathrm{Si}$ as the dominant element, whose state is $\mathrm{SiO}_{2}$. Aluminum existed as $\mathrm{Al}_{2} \mathrm{O}_{3}$ form. These results are in agreement with the composition of the 
Fig. 3 SEM of BXE ALKCAT zeolites
Label $x$ Z Zets

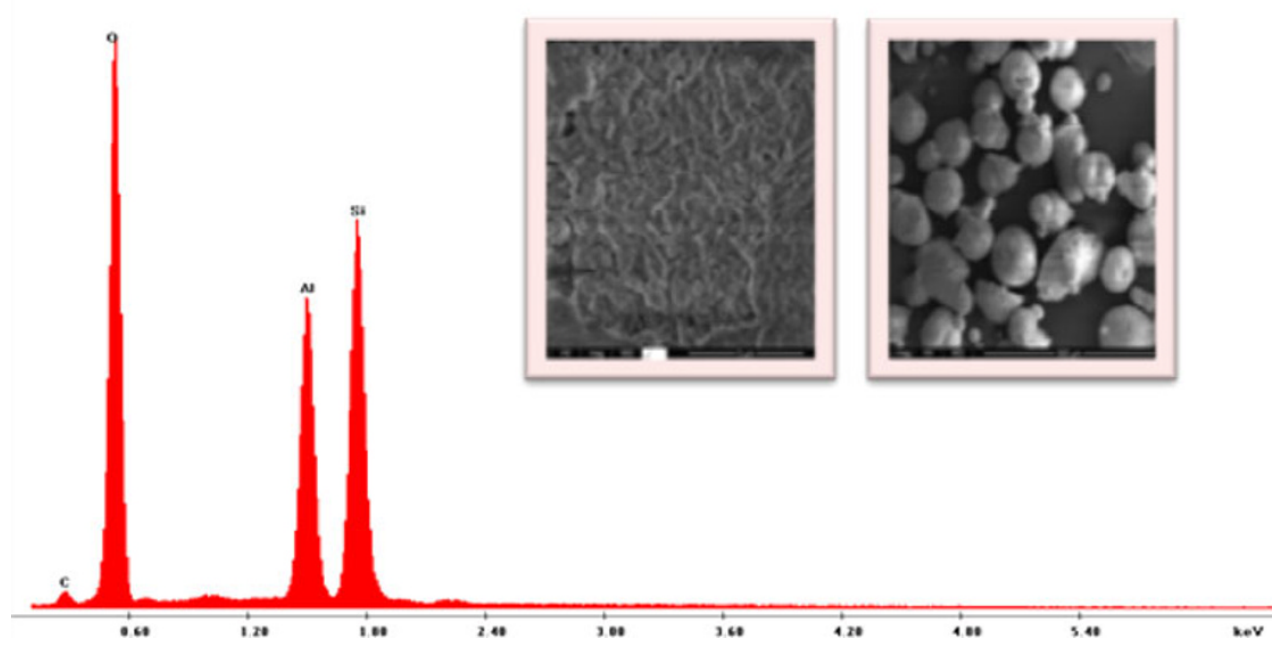

Fig. 4 BET surface area of zeolite

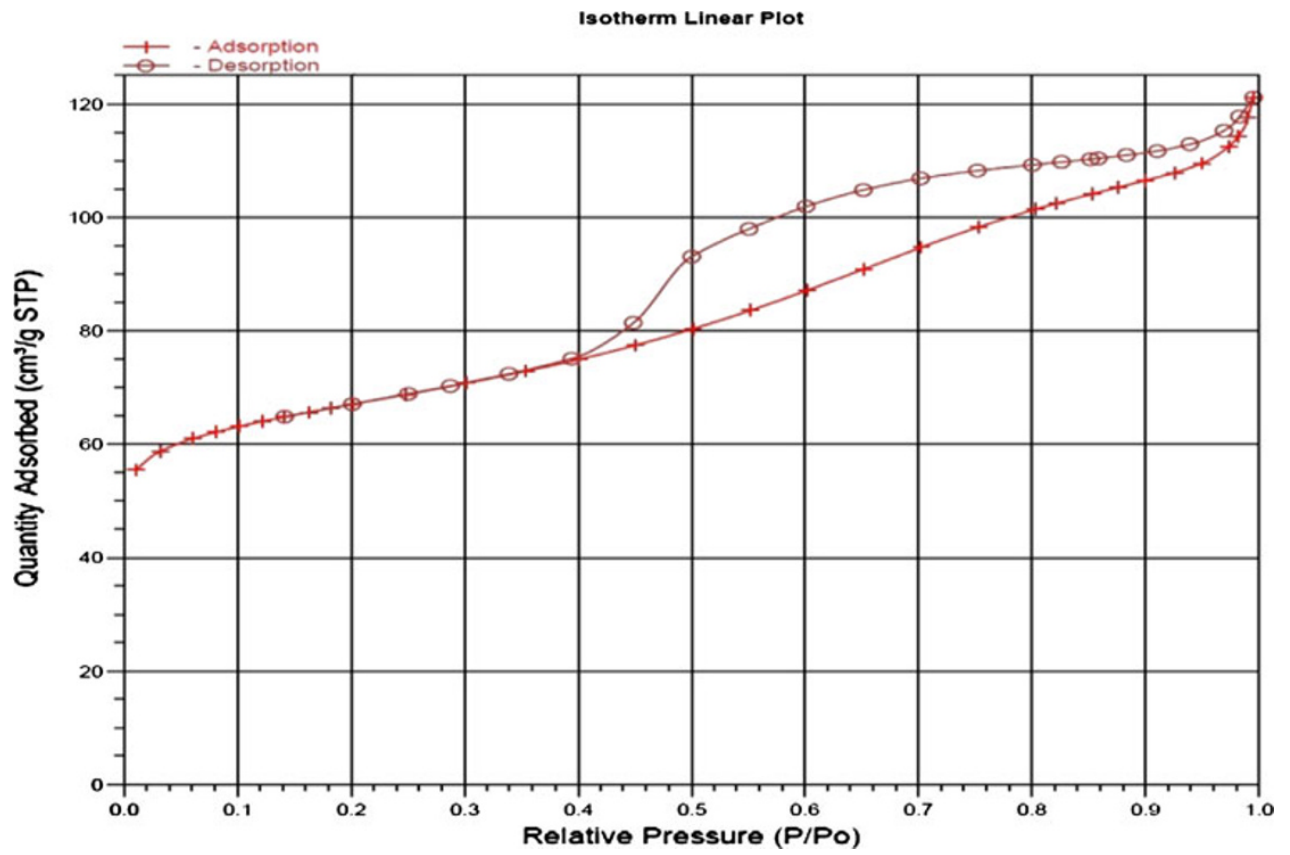

zeolite and kaolinite, and it is shown that the surface has less - $\mathrm{OH}$ groups, which is the main component of Bronsted acid site.

\section{Differential thermal analysis of catalyst}

In order to investigate the stability of zeolite catalyst at various temperatures, DTA was performed on zeolite by heating the sample up to $1,100{ }^{\circ} \mathrm{C}$ with a rate of heating $40{ }^{\circ} \mathrm{C} / \mathrm{min}$. The first sharp peak at $80{ }^{\circ} \mathrm{C}$ might result from the water or vapor desorption. The continuous endothermic curve is due to the loss of the hydroxyl group over the catalyst. Overall, it was found that the catalyst is thermally stable over a wide range of temperature ranging from 25 to $1,100{ }^{\circ} \mathrm{C}$ as shown in Fig. 8 .

Catalyst evaluation

\section{Effect of reaction temperature on benzene conversion}

The alkylation of benzene with ethylene was carried out at 300, 350, 400 and $450{ }^{\circ} \mathrm{C}$ over BXE ALKCAT zeolite catalyst. The conversion of benzene and the product selectivity are presented in Figs. 9, 10, 11 and 12. 


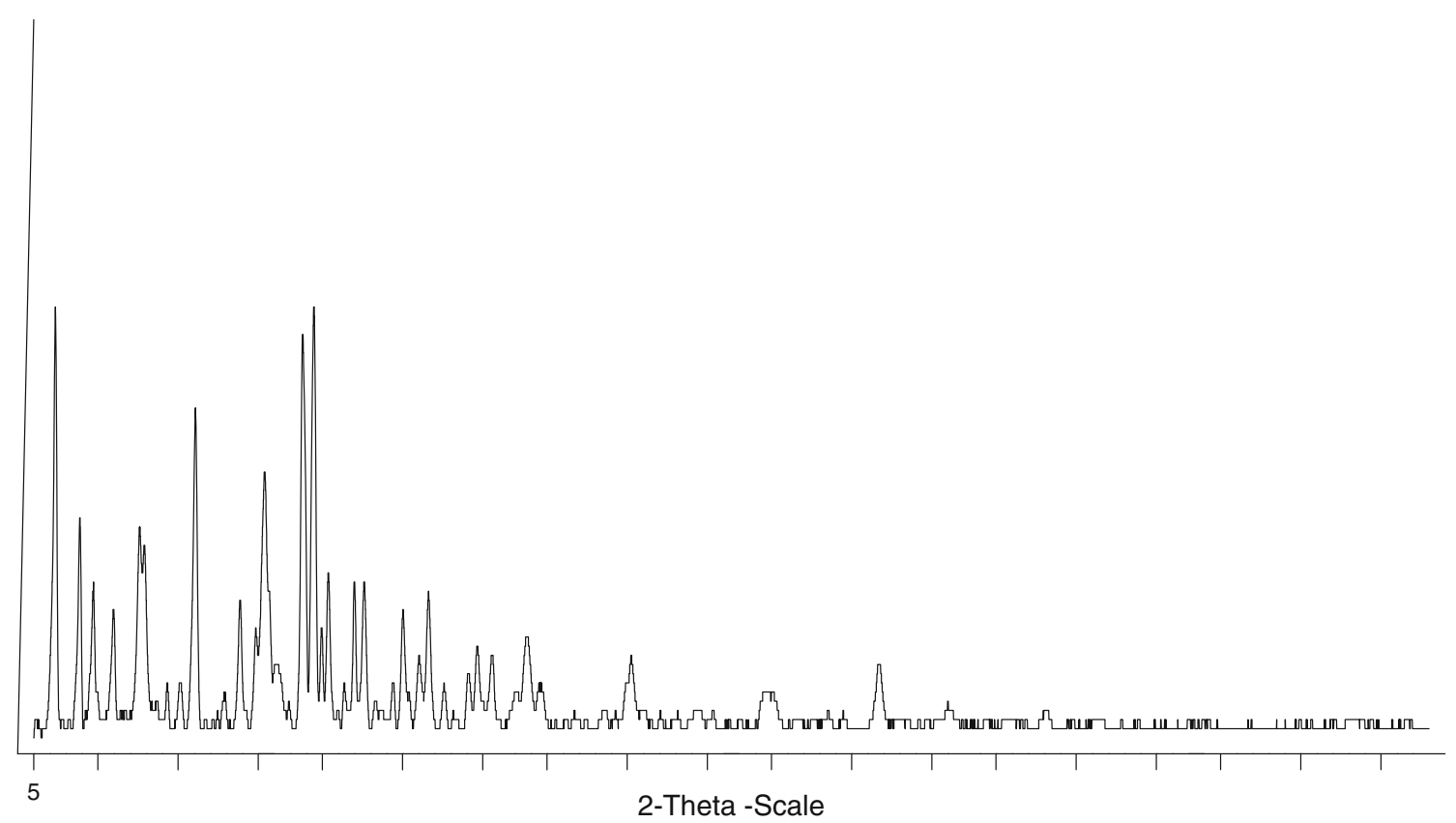

Fig. 5 XRD analysis of the ZSM-5/kaolinite catalyst for the alkylation reaction

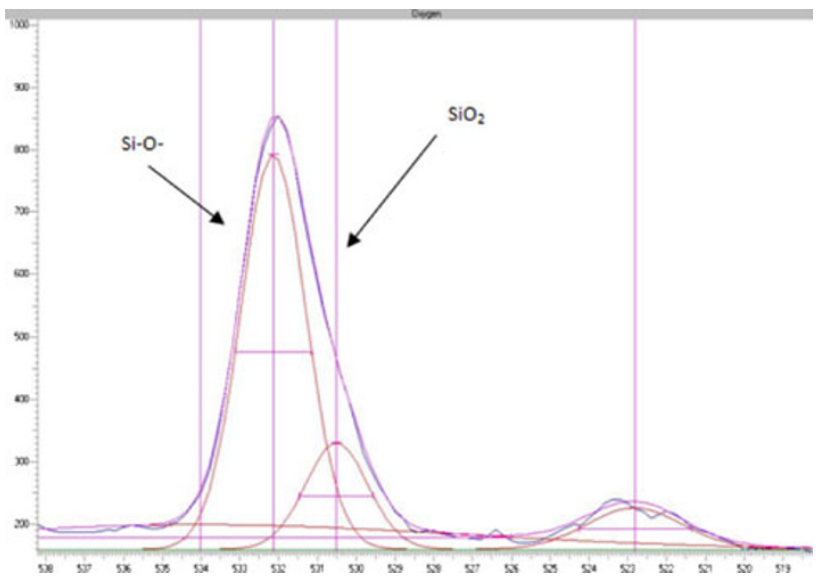

Fig. 6 Curve fitting XPS spectrum of O 1s of zeolite

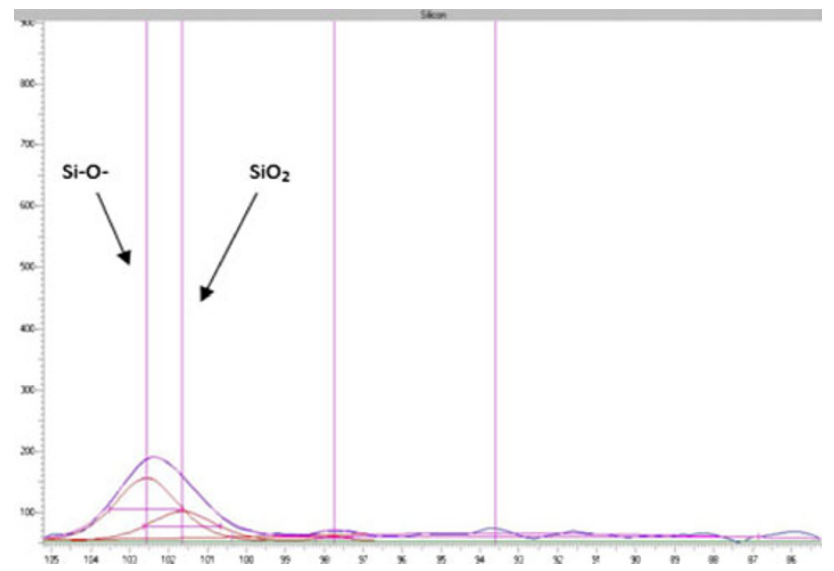

Fig. 7 Curve fitting XPS spectrum of $\mathrm{Si} 2 \mathrm{P}_{1 / 2}$ of zeolite
Conversion of benzene increases from 300 to $400{ }^{\circ} \mathrm{C}$, and a slight decrease in the conversion of benzene was observed as the temperature was increased further up to $450{ }^{\circ} \mathrm{C}$. Benzene conversions of approximately $6.5,13$, and $63 \%$ were achieved at 300,350 and $400{ }^{\circ} \mathrm{C}$, respectively, while slightly decrease from 63 to $57 \%$ as the temperature was increased from 400 to $450{ }^{\circ} \mathrm{C}$, respectively, for a reaction time of $0.5 \mathrm{~h}$, and mole ratio of $\mathrm{BZ}$ to $\mathrm{E} 1: 1$. This can be explained by the endothermicity of the alkylation reaction. High reaction temperature favors the conversion, and also the high temperature can increase the activity of the acidic site; thus, the reaction should be carried out at a relatively high temperature.

\section{The effect of time-on-stream}

The effect of time-on-stream on benzene conversion and EB selectivity was studied over BXE ALKCAT zeolite catalyst using a feed stock mole ratio ranging from 1:1 to 6:1 under variable temperatures. Reaction conditions and results are presented in Figs. 9, 10 and 11. It is shown that the $\mathrm{BZ}: \mathrm{E}=1: 1$, the $\mathrm{BZ}$ conversion drops more quickly than over the other catalysts, while practically no changes are observed in selectivity for EB and DEB isomers after about $2 \mathrm{~h}$ on stream. Increase of BZ:E decreases the benzene conversion, which is in fact due to the excessive feeding of benzene, to depress the carbon formation; but, the catalyst has a much stable conversion, which is due the depression of carbon formation by the benzene. 
Fig. 8 Differential thermal analysis (DTA) thermogram of zeolite

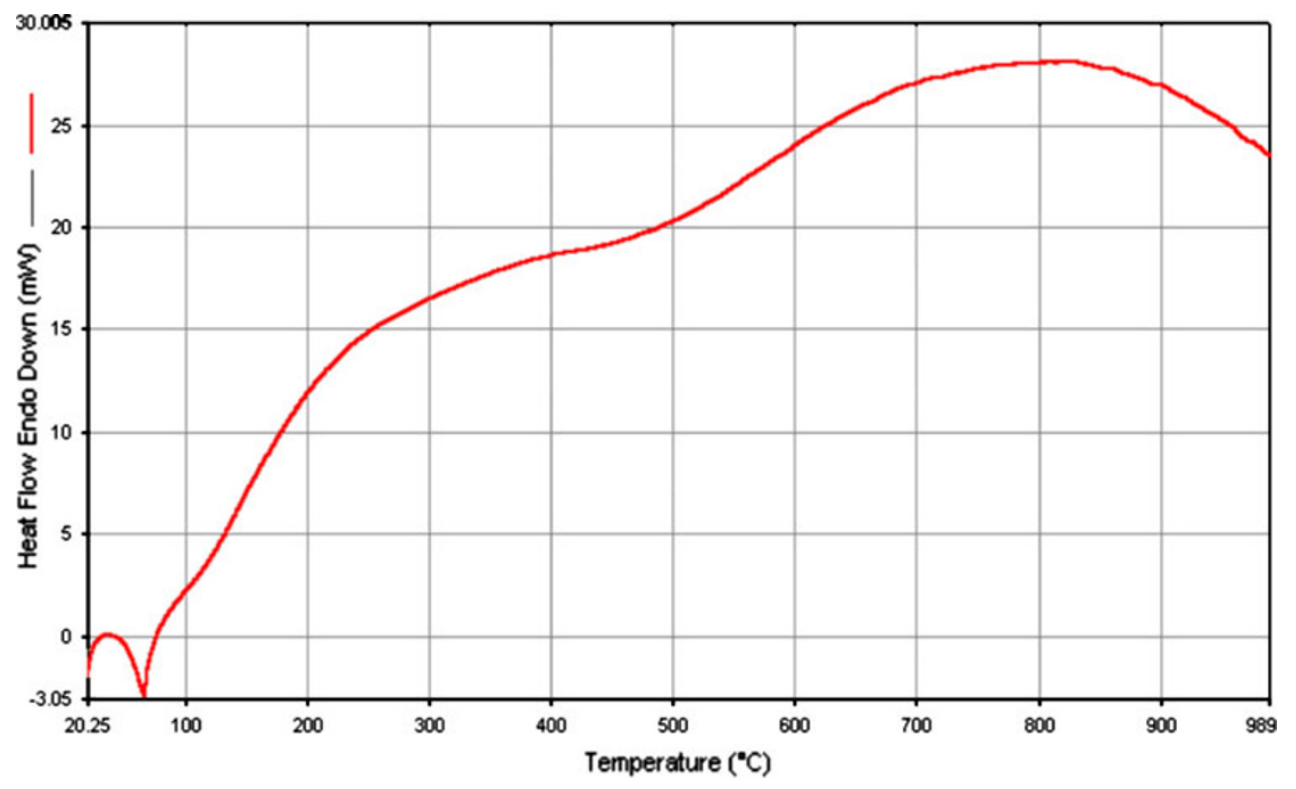

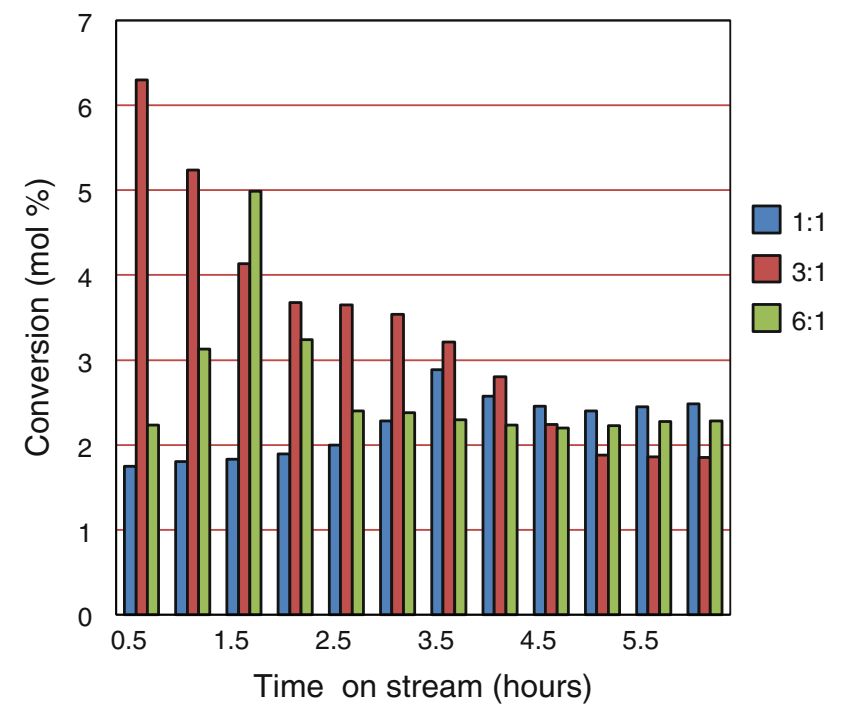

Fig. 9 Conversion of benzene with time for zeolite catalyst at $300{ }^{\circ} \mathrm{C}$

\section{Effect of reaction temperature on the yield and selectivity} of ethylated products

The major product of the alkylation reaction over $\mathrm{BXE}$ ALKCAT zeolite catalyst is EB. The yield of EB increases as the temperature increases from 300 to $450{ }^{\circ} \mathrm{C}$ with different mole ratios of $\mathrm{BZ}$ to $\mathrm{E}$ : the reason has been given before. The maximum yield was obtained about $50 \%$ with 1:1 molar ratio of $\mathrm{BZ}$ to $\mathrm{E}$ at $450{ }^{\circ} \mathrm{C}$ for the reaction time $0.5 \mathrm{~h}$ as shown in Fig. 13.

The maximum yield $17 \%$ of DEB (o-, $m-$, and $p$-) isomers was obtained at $400{ }^{\circ} \mathrm{C}$ with mole ratio of $\mathrm{BZ}$ to $\mathrm{E}$ $1: 1$. There is variable trend of the formation of DEB isomers under the same mole ratio $\mathrm{BZ}$ to $\mathrm{E}$ and variable temperatures. The yield of DEB isomers increases as the

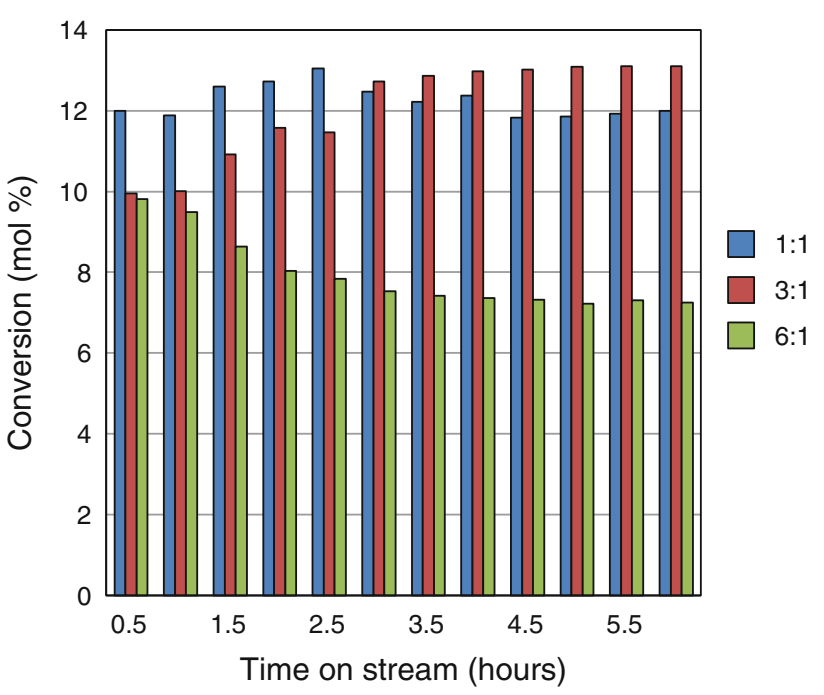

Fig. 10 Conversion of benzene with time for zeolite catalyst at $350{ }^{\circ} \mathrm{C}$

temperature changes from 300 to $400{ }^{\circ} \mathrm{C}$ and then decreases as the temperature increased up to $450{ }^{\circ} \mathrm{C}$ as shown in Fig. 14. This is probably due to transalkylation of DEB isomers with benzene as shown in Scheme 1.

Based on these results, it is inferred that the increase of the reaction temperature makes more active sites available for the alkylation reaction, awhile more side reactions also occurs. However, overall, the EB yield increases with the temperature, due to high increase in the conversion rate.

Selectivity for EB was affected by temperature. The selectivity for EB decreased constantly as the temperature increased from 300 to $400{ }^{\circ} \mathrm{C}$ and then increases as the temperature increases up to $450{ }^{\circ} \mathrm{C}$ as shown in Fig. 15. The increase in selectivity is probably due to 


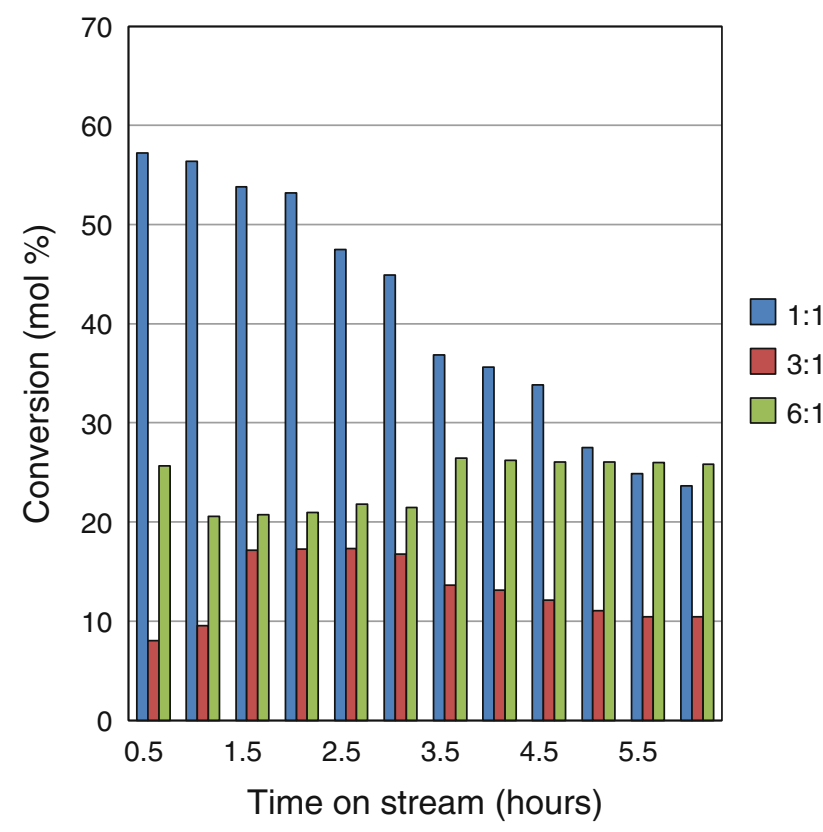

Fig. 11 Conversion of benzene with time for zeolite catalyst at $400{ }^{\circ} \mathrm{C}$

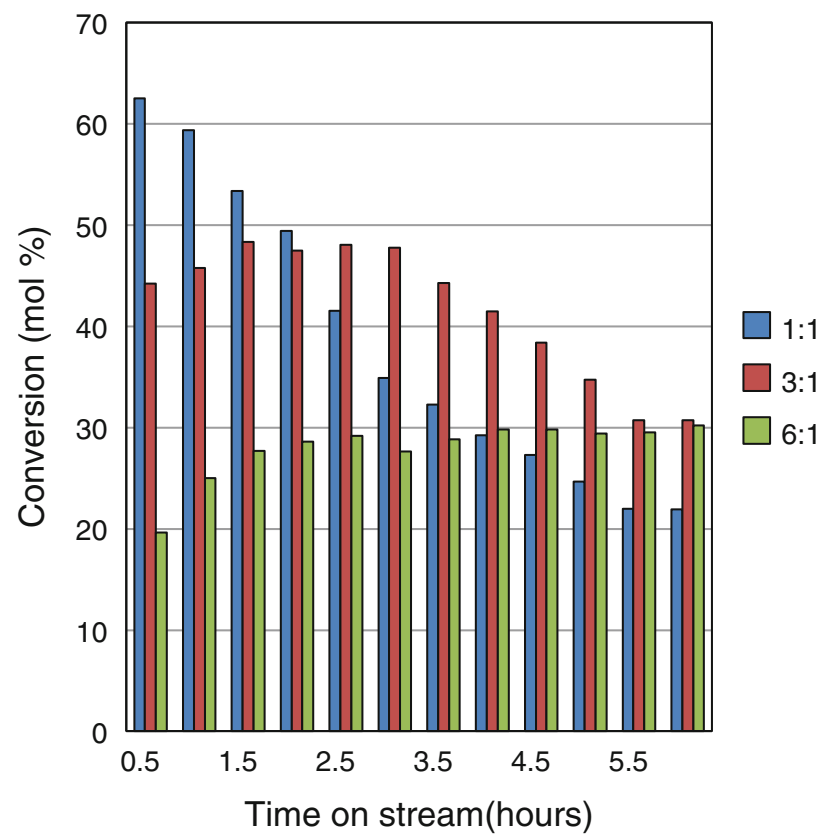

Fig. 12 Conversion of benzene with time for zeolite catalyst at $450{ }^{\circ} \mathrm{C}$

transalkylation reactions between benzene and diethylbenzene (o-, $m$-, and $p$-) isomers as shown in Scheme 1.

The effect of feed stock mole ratio the yield and selectivity of ethylated products

The effect of feed stock mole ratio on ethylbenzene yield and product selectivity was studied by varying the feed mole ratios of $\mathrm{BZ}$ to $\mathrm{E}$ from 1:1 to 6:1 over BXE ALKCAT zeolite catalyst at variable temperatures, and the results are presented in Figs. 16, 17 and 18. The yield of ethylbenzene shows a significant decline as mole ratios of benzene to ethylene increased from $1: 1$ to $6: 1$ at temperatures of $300,350,400$, and $450{ }^{\circ} \mathrm{C}$. This is because of the increased dilution of ethylene by benzene. With lower ethylene content in the feed, the probability of ethylene interaction with benzene is reduced and a lower ethylbenzene yield is obtained. In addition, the excessive feeding of benzene would give a overall low conversion, even all the ethylene is consumed. The maximum of about $50 \%$ yield was obtained with 1:1 molar ratio of $\mathrm{BZ}$ to $\mathrm{E}$ at $450{ }^{\circ} \mathrm{C}$

However, yield for the other alkylated products such as diethylbenzene $(o-, m-$, and $p$-) isomers decreased as the mole ratio of $\mathrm{BZ}$ to $\mathrm{E}$ increased. The increase in the yield of $\mathrm{EB}$ and diethylbenzene isomers results from a high conversion of $\mathrm{BZ}$ as the mole ratio of $\mathrm{BZ}$ to $\mathrm{E}$ decreases. At higher mole ratios of $\mathrm{BZ}$ to $\mathrm{E}$, the accessibility of ethyl cations to yield diethylbenzene isomers by further alkylation of EB was reduced.

Selectivity for EB increased as the ratio of benzene to ethylene increased with lower conversion of benzene. The same trends were observed at temperatures of 300, 350, 400 , and $450{ }^{\circ} \mathrm{C}$. The maximum selectivity to EB (85\%) with higher conversion of benzene was obtained with a mole ratio of $1: 1$ at $450{ }^{\circ} \mathrm{C}$, while $73 \%$ with $1: 1$ at $300{ }^{\circ} \mathrm{C}$.

\section{Coke formation}

In the alkylation of $\mathrm{BZ}$ with $\mathrm{E}$, the deactivation of catalysts usually occurs as active sites are blocked by coke formation. The coking mostly results from the oligomerization of ethylene, because activated ethylene easily reacts with other ethylene molecules to form higher polymer. This is the reason the industry always use excessive benzene, which is to increase the ethylene benzene selectivity and depress the coke formation. The carbon balance was calculated as the following: (1) number of moles of carbon of benzene and ethylene in the feedstock, (2) number of moles of carbon of the unreacted ethylene, and reaction products (unreacted benzene, ethylbenzene, and $m$-, $p$-, o-diethylbenzenes), and (3) carbon deposited on the catalyst as obtained from TGA results (Table 1). It was found that the errors are ranging from 5 to $\pm 10 \%$.

\section{Conclusion}

A kaolinite-supported ZSM-5 zeolite catalyst has been prepared using prilling process. The catalyst has stable 
Fig. 13 Yield of EB at variable temperatures using different mole ratio of $\mathrm{BZ}: \mathrm{E}$ under atmospheric pressure

Fig. 14 Yield of EB and DEB at variable temperatures using different mole ratio of $\mathrm{BZ}: \mathrm{E}$ under atmospheric pressure
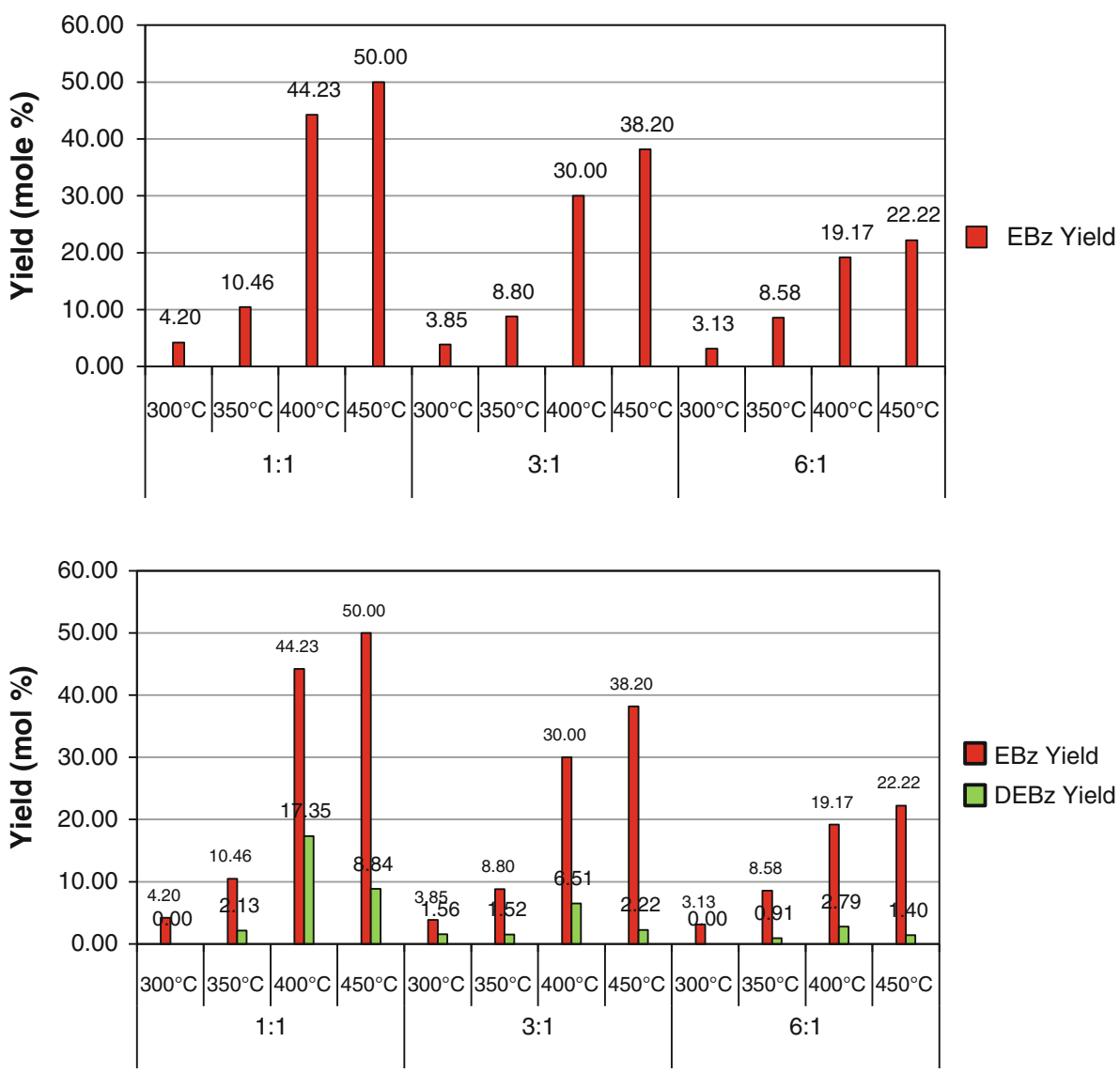

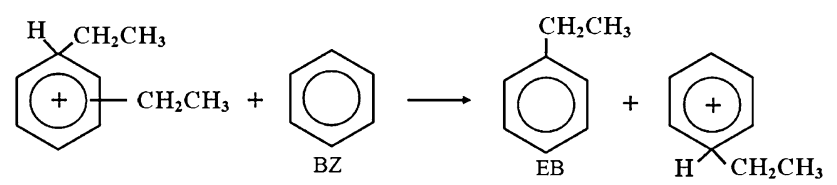<smiles>CCc1ccccc1</smiles>

Scheme1 Transalkylation reaction of diethylbenzene isomers with benzene structure, with surface mainly composed of $\mathrm{SiO}_{2}$. The catalyst has been tested in the alkylation of the benzene with ethylene. It is found that the catalyst showed high selectivity to ethylbenzene at low temperature and high benzene to ethylene ratio.

The prepared catalyst has high stability at high benzene to ethylene ratio, and high yield of ethylbenzene. The increase of reaction temperature gives higher benzene conversion, but a low with more side products. Higher benzene to ethylene ratio helps to depress the side reaction, but lead to lower conversion of benzene due to the excess feeding.
Fig. 15 Selectivity of EB at variable temperatures using different mole ratio of $\mathrm{BZ}: \mathrm{E}$ under atmospheric pressure

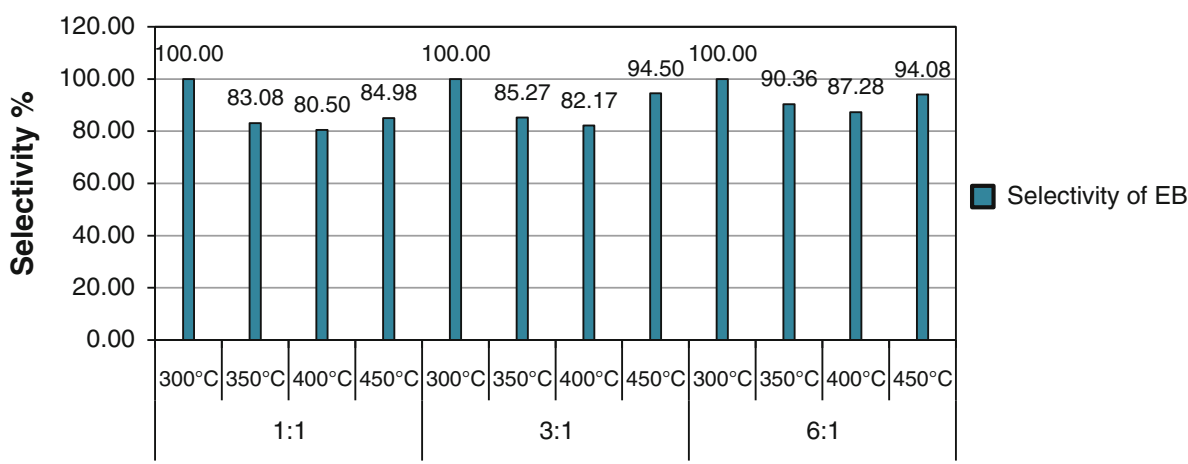


Fig. 16 Yield of EB using different mole ratio of BZ:E at variable temperatures and under atmospheric pressure

Fig. 17 Yield of EB and DEB using different mole ratio of $\mathrm{BZ}: \mathrm{E}$ at variable temperatures and under atmospheric pressure

Fig. 18 Selectivity of EB using different mole ratio of $\mathrm{BZ}: \mathrm{E}$ at variable temperatures and under atmospheric pressure
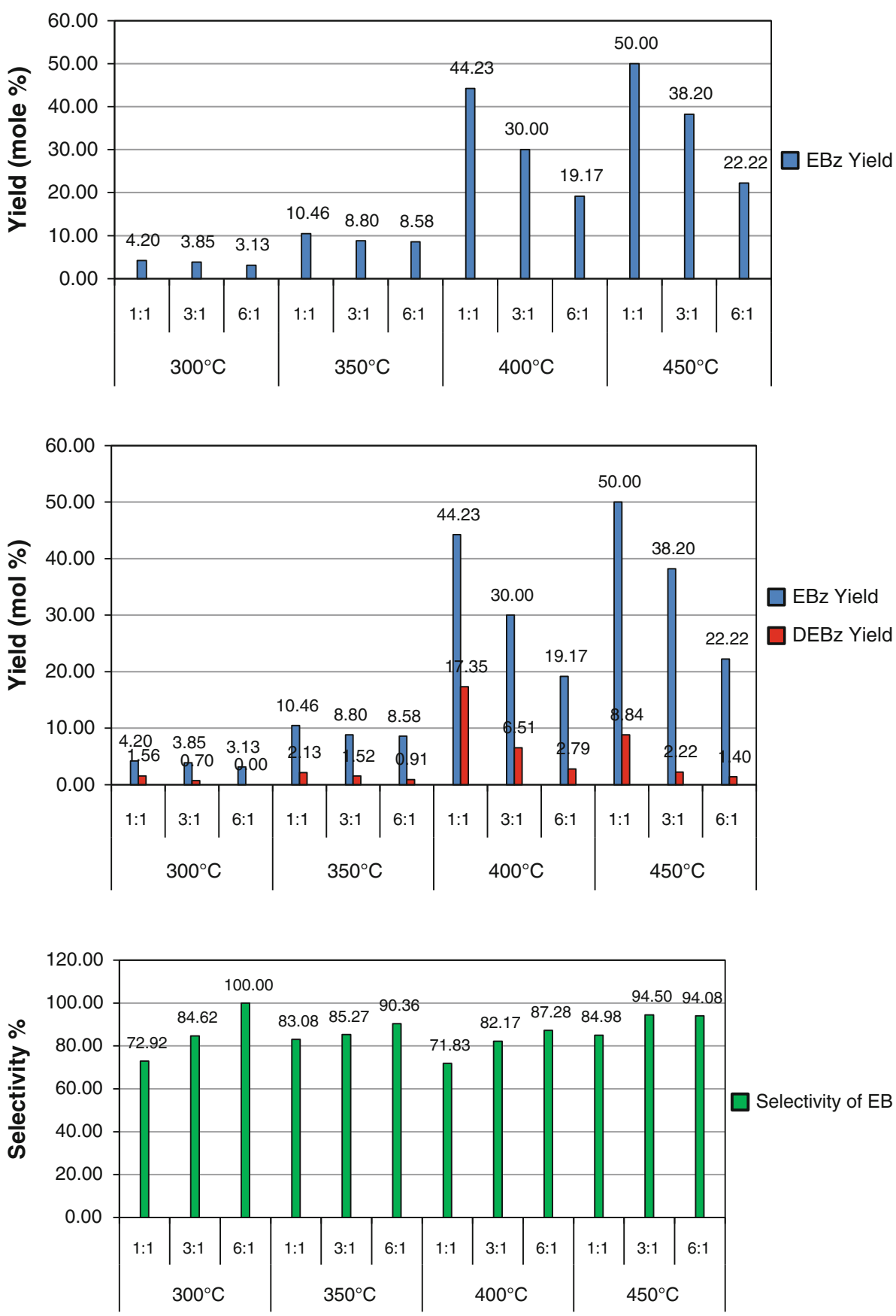

Table 1 Thermal gravimetric analysis (TGA) results for carbon deposition balancing with 6:1 mol ratio at variable temperature

a Heating rate: $10 \mathrm{ml} / \mathrm{min}$
b Heating rate: $40 \mathrm{ml} / \mathrm{min}$

a Heating rate: $10 \mathrm{ml} / \mathrm{min}$
b Heating rate: $40 \mathrm{ml} / \mathrm{min}$

\begin{tabular}{|c|c|c|c|c|}
\hline & Starting weight $(\mathrm{g})$ & Un-subtracted weight $(\%)$ & Final weight $(\mathrm{g})$ & Balance $(\mathrm{g})$ \\
\hline Zeolite $^{\mathrm{a}}$ & 11.238 & 85.85130 & 9.648 & 1.59 \\
\hline Zeolite $^{\mathrm{b}}$ & 10.282 & 85.60697 & 8.802 & 1.48 \\
\hline $300{ }^{\circ} \mathrm{C}$; Zeolite ${ }^{\mathrm{a}}$ 6:1 & 10.658 & 83.47701 & 8.907 & 1.751 \\
\hline $300{ }^{\circ} \mathrm{C}$; Zeolite ${ }^{\mathrm{b}}$ 6:1 & 10.275 & 82.67406 & 8.497 & 1.778 \\
\hline $350{ }^{\circ} \mathrm{C}$; Zeolite ${ }^{\mathrm{a}}$ 6:1 & 10.366 & 84.58893 & 8.769 & 1.597 \\
\hline $350{ }^{\circ} \mathrm{C}$; Zeolite ${ }^{\mathrm{b}}$ 6:1 & 9.429 & 84.25536 & 7.955 & 1.474 \\
\hline $400{ }^{\circ} \mathrm{C}$; Zeolite ${ }^{\mathrm{a}}$ 6:1 & 11.191 & 88.01292 & 9.861 & 1.33 \\
\hline $400{ }^{\circ} \mathrm{C}$; Zeolite ${ }^{\mathrm{b}}$ 6:1 & 12.830 & 87.37062 & 11.217 & 1.613 \\
\hline
\end{tabular}


There is carbon deposition occurred over the BXE ALKC at catalysts, which accounts for about $10 \%$ of carbon, even the catalyst is still active, which suggest that the carbon may not be the poison for the catalyst active site.

The optimal operation conditions for the BXE ALKCAT are relatively high temperature $350-400{ }^{\circ} \mathrm{C}$ and high benzene to ethylene ratio to give high yield and high selectivity of ethylbenzene over the catalyst.

Acknowledgments We would like to thank Dr. Turki bin Saud bin Mohammad Al Saud, the Vice President for Research Institutes for his valuable support and funding the joint research. Also, I would like to thank the alkylation research team: Eng. Khalid S. Al-Ghamdi, Abdullah J. Al-Ghamdi, Sami D. Al-Dress, Waleed A. Al-Suwaylih and Sami D. Al-Zahrani.

Open Access This article is distributed under the terms of the Creative Commons Attribution License which permits any use, distribution, and reproduction in any medium, provided the original author(s) and the source are credited.

\section{References}

1. Al-Kinany MC, Al-Khowaiter SH (1998) Ethylation and isopropylation of benzene using superacid catalyst. In: Proceedings of 15th World Petroleum Congress. vol 2, pp 830-834

2. Cejka J, Wichterlova B, Bednarova S (1991) Alkylation of toluene with ethene over H-ZSM-5 zeolites. Appl Catal A 79(2): 215-226
3. Hansen $N$ et al (2008) Theoretical investigation of benzene alkylation with ethene over H-ZSM-5. J Phys Chem C 112(39): 15402-15411

4. Hansen N et al (2010) Quantum chemical modeling of benzene ethylation over H-ZSM-5 approaching chemical accuracy: a hybrid MP2:DFT study. J Am Chem Soc 132(33):11525-11538

5. Kartal OE, Onal I (2008) Synthesis of ZSM-5 from modified clinoptilolite and its catalytic activity in alkylation of benzene to ethylbenzene. Chem Eng Commun 195(8):1043-1057

6. Bassler EJ et al (1999) Upgrade by catalytic process technology. Hydrocarbon Eng 4(7):36-40

7. Dwyer FG (1981) Mobil/Badger ethylbenzene process-chemistry and catalytic implications. Chem Ind (Dekker) 5:39-50

8. Ebrahimi AN et al (2011) Modification and optimization of benzene alkylation process for production of ethylbenzene. Chem Eng Process 50(1):31-36

9. Hansen $N$ et al (2009) Analysis of diffusion limitation in the alkylation of Benzene over H-ZSM-5 by combining quantum chemical calculations, molecular simulations, and a continuum approach. J Phys Chem C 113(1):235-246

10. Liu J et al (1999) The carbon depositing behavior and its kinetic research in benzene alkylation process over high silicate ZSM-5 zeolite. J Therm Anal Calorim 58(2):375-381

11. Song Y et al (2006) Coke burning behavior of a catalyst of ZSM5/ZSM-11 co-crystallized zeolite in the alkylation of benzene with FCC off-gas to ethylbenzene. Fuel Process Technol 87(4): 297-302

12. Hassan M, El-Shall H (2009) Texture and microstructure of thermally treated acid-leached kaolinitic clays. Adsorpt Sci Technol 27(7):671-684

13. Suraj $\mathrm{G}$ et al (1997) The effect of micronization on kaolinites and their sorption behavior. Appl Clay Sci 12(1-2):111-130

14. Westlake DJ, Atkins MP, Gregory R (1985) The use of layered clays for the production of petrochemicals. Acta Phys Chem 31(1-2):301-308 